\author{
I. M. Kadenko ${ }^{1}$, V. A. Plujko ${ }^{1}$, B. M. Bondar ${ }^{1,2}$, \\ O. M. Gorbachenko ${ }^{1}$, B. Yu. Leshchenko ${ }^{1,3}$, K. M. Solodovnyk ${ }^{1}$

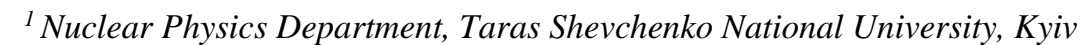 \\ ${ }^{2}$ All-Ukrainian Center for Radiosurgery of the Clinical Hospital "Feofania”, Kyiv \\ ${ }^{3}$ National Technical University of Ukraine "Kyiv Polytechnic Institute”, Kyiv
}

\title{
PROMPT GAMMA-RAYS FROM FAST NEUTRON CAPTURE IN ${ }^{\text {nat} N i}$
}

The yield of prompt $\gamma$-rays produced by interaction of $14 \mathrm{MeV}$ neutrons with ${ }^{\text {nat }} \mathrm{Ni}$ was measured using the time-offlight technique. A differential cross section from ( $\mathrm{n}, \mathrm{x} \gamma)$ reactions was unfolded from amplitude spectrum. Experimental results were compared with theoretical calculations performed using EMPIRE 3.2 and TALYS 1.6 codes. The effect of average characteristics of nuclear excited states on calculated gamma ray spectrum was studied.

Keywords: fast neutrons, time-of-flight method, gamma-ray spectrum, Hauser - Feshbach model, photon strength function, nuclear level density

\section{Introduction}

The $\gamma$-ray yield induced by interaction of fast neutrons with atomic nuclei of the reactor materials are of great importance for the reactor core calculations [1]. It is, for example, requested for the estimation of energy release, $\gamma$-ray shielding and radiation swelling of the reactor pressure vessel internals. Apart from nuclear and radiation safety aspects the analysis of $(\mathrm{n}, \mathrm{x} \gamma)$ reaction cross sections provides valuable information about the fundamental properties of nuclear processes and nuclear excited states. Specifically, these data allow to study the contributions of different nuclear reaction mechanisms, level density of excited states and characteristics of their decay.

Despite numerous experimental measurements performed with $14.1 \mathrm{MeV}$ neutrons, there are still no data for $\gamma$-spectrum in full energy range (up to excitation energy of nucleus) obtained within the same experiment (except measurements of the Kyiv group [2 - 8]). Furthermore, there are disagreements between the results of different authors. In this contribution we present the results of measurements of $\gamma$-spectrum from (n, x $\gamma$ ) reactions on ${ }^{\text {nat }} \mathrm{Ni}$ for gamma-ray energies from 2 to $22 \mathrm{MeV}$. The differential cross sections were unfolded from the amplitude spectrum and cross section uncertainties were estimated. The experimental results were compared with theoretical calculations performed using EMPIRE 3.2 and TALYS 1.6 codes for statistical models of compound and precompound decays. The impact of different expressions for photon strength function and nuclear level density on the calculation results for ${ }^{\text {nat }} \mathrm{Ni}$ was considered.

\section{Measurements and experimental results}

The measurements of the instrumental $\gamma$-spectra were performed using scintillation spectrometer based on $150 \times 100 \mathrm{~mm} \mathrm{NaI(Tl)}$ detector. Neutron pulse generator (NPG-200), designed and manufactured at Nuclear Physics Department of Taras Shevchenko National University of Kyiv, was used as a neutron source. Time-of-flight method was applied for separation of prompt $\gamma$-rays from neutrons, background and rescattered $\gamma$-rays. The block diagram of the experiment and the data acquisition system are schematically represented in Fig. 1.

The reaction ${ }^{3} \mathrm{H}(\mathrm{d} ; \mathrm{n}){ }^{4} \mathrm{He}$ on Ti-T target of NPG200 is used to generate fast neutrons. Deuterons are accelerated up to $130 \mathrm{keV}$ energy by low-voltage accelerator with klystron bunching of the beam. Pulse generation frequency is equal to $7.25 \mathrm{MHz}$, average neutron intensity $\mathrm{I} \approx 10^{7} \mathrm{~s}^{-1}$. The NPG-200 is mounted inside a room of $10 \times 6 \times 4.5 \mathrm{~m}$ dimensions. For minimization of the effects from rescattered neutrons and gamma rays, Ti-T target is placed in a center of the room. The distance between Ti-T target and the nearest walls is $3 \mathrm{~m}$ and the height of the neutron source location above the floor is $1.5 \mathrm{~m}$.

The ${ }^{\text {nat }} \mathrm{Ni}$ sample has the ring torus shape with the main radius $R_{S}=10.0 \mathrm{~cm}$ and minor radius $r_{S}=1.5 \mathrm{~cm}$. The center of the sample is positioned at neutron source output. In this ring geometry the sample is irradiated by neutrons with the energy of $14.1 \pm 0.2 \mathrm{MeV}$. The neutron energy uncertainty is due to finite dimensions of the torus sample, which leads to interactions of target nuclei with neutrons emitted at different angles within $90 \pm 10^{\circ}$ angle interval. The neutron beam monitoring is performed by the use of additional plastic scintillator (PS) detector with sizes $\varnothing 30 \times 40 \mathrm{~mm}$. This detector was placed at a distance $L_{M}=3.36 \mathrm{~m}$ from Ti-T target. The angle between the deuteron beam and the PS detector is $\theta_{M}=140^{\circ}$ (the neutron beam has the energy $13.5 \mathrm{MeV}$ in this direction). 


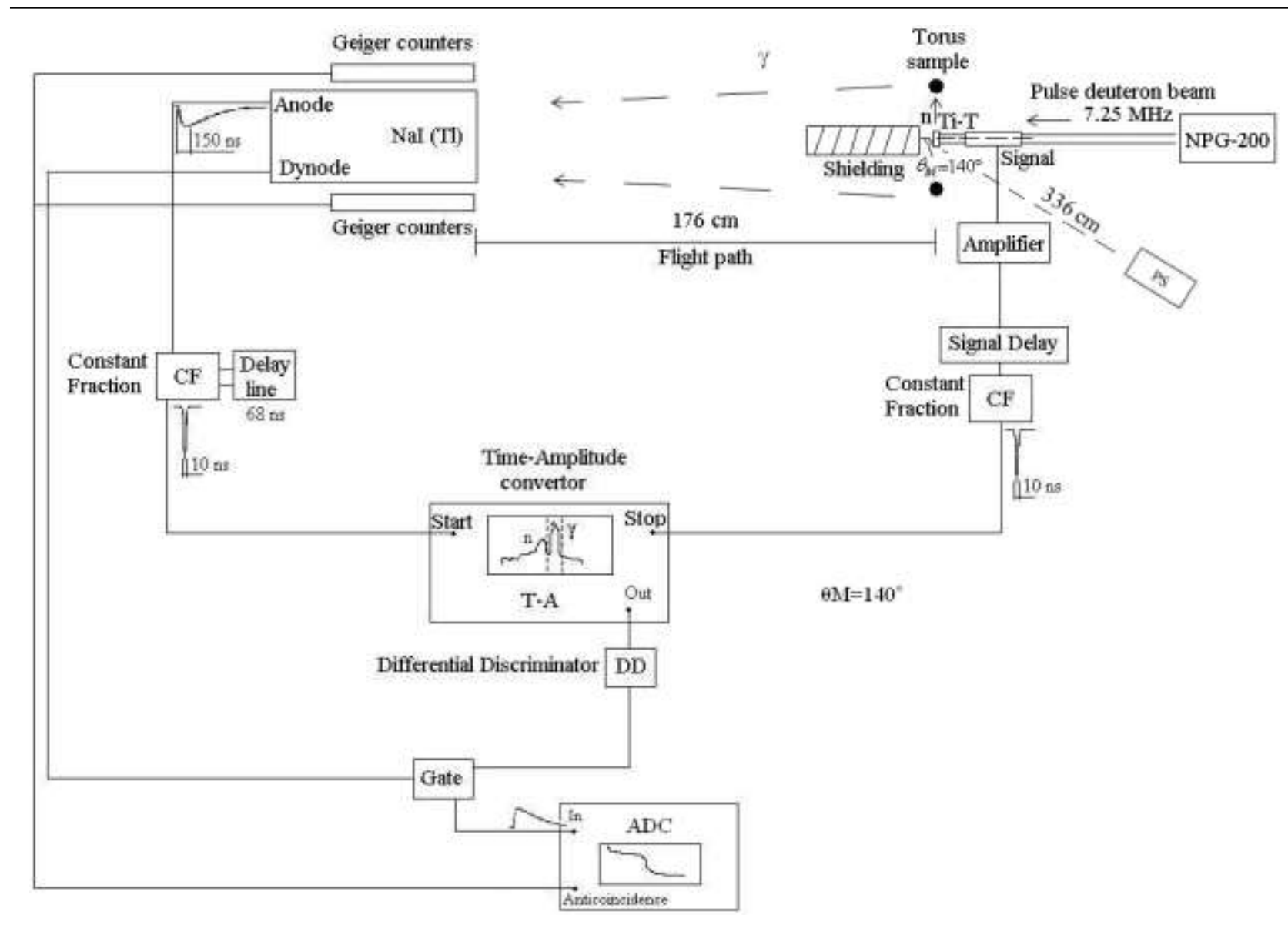

Fig. 1. Block diagram of the experiment and data acquisition system.

The emitted prompt gamma-rays are traversed the flight path and detected by the $\mathrm{NaI}(\mathrm{Tl})$ scintillator cylindrical detector of sizes $\varnothing 2 r_{d} \times h_{d} \equiv \varnothing 150 \times$ $\times 100 \mathrm{~mm}$. The flight path $\left(L_{F}\right)$ equals $1.76 \mathrm{~m}$ to ensure reliable separation of prompt $\gamma$-rays from neutron and $\gamma$-ray background. The additional shielding is installed between the neutron source and detector for absorption of primary neutron beam. The time selection of events is carried out by the use of timeamplitude converter and differential discriminator.

The "start" signals were fed from the detector and the "stop" signals were delivered from the signal electrode that points the moment of the neutron generation pulse. This sequence of "start" and "stop" signals was chosen to avoid the high pulse intensities in spectrometer and to minimize the loss of relevant signals in detector. For reducing influence of cosmic rays, the $\mathrm{NaI}(\mathrm{Tl})$ detector was surrounded by Geiger counters working in anti-coincidence mode with spectrometer signals. The $\mathrm{NaI}(\mathrm{Tl})$ detector and Geiger counters were placed in a special composed shielding with concrete and lead bricks.

The energy calibration of the $\mathrm{NaI}(\mathrm{Tl})$ detector was performed with adoption of linear relationship between the energy deposit $\varepsilon$ in the detector volume from gamma-rays and the number $N$ of amplitudeto-digital convertor (ADC) channels. Parameters of this relationship were determined using experimental data of full absorption peaks of $4.43 \mathrm{MeV}$ gamma rays from neutron inelastic scattering on ${ }^{12} \mathrm{C}$ and $2.64 \mathrm{MeV}$ gamma-rays from ${ }^{208} \mathrm{Tl}$ isotope. The results of the calibration can be seen by comparing values on the lower and upper scales in Fig. 2.

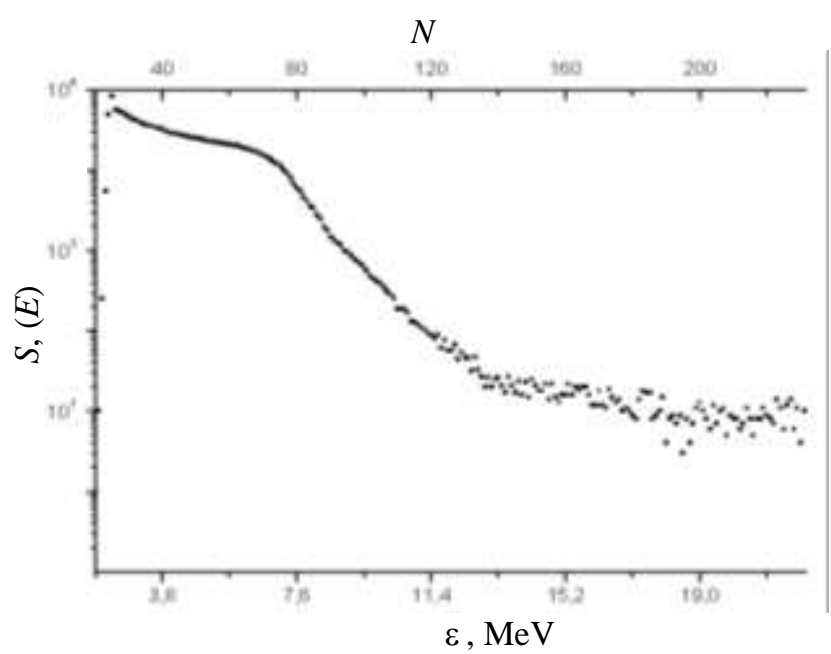

Fig. 2. Measured amplitude distribution spectrum of $\gamma$-rays from ${ }^{\text {nat }} \mathrm{Ni}(\mathrm{n}, \mathrm{x} \gamma)$ reactions with $14.1 \mathrm{MeV}$ neutrons: $N$-amplitude channel number; $\varepsilon$ - the energy deposited in the detector. 
The subject of interest was the amplitude spectrum $S_{\gamma}$ of prompt gamma-rays detected in a detection solid angle $\Delta \Omega$ near the scattering angle $\theta_{\gamma}=90^{\circ}$ with and without the torus sample. Amplitude spectrum $S_{\gamma}$ has a histogram form and corresponds to distribution of the number of counts acquired in the channels of the amplitude analyzer with energies $\varepsilon_{i} \pm \Delta \varepsilon / 2$ within interval $2 \leq \varepsilon_{i} \leq 22 \mathrm{MeV} \quad(i=1 \div N)$ corresponding to $N=$ $=230$ ADC channels. The energy deposit width $\Delta \varepsilon$ was taken according to the energy resolution of the $\mathrm{NaI}(\mathrm{Tl})$ detector $(\Delta E / E=16 \%$ for $2.64 \mathrm{MeV})$ and was equal to $\Delta \varepsilon \cong 0.1 \mathrm{MeV}$ ensuring optimal number of channels in full absorption peaks.

In Fig. 2 the measured amplitude distribution spectrum $S_{\gamma}(\varepsilon)$ of gamma-rays from ${ }^{\text {nat }} \mathrm{Ni}(\mathrm{n}, \mathrm{x} \gamma)$ reactions is given as a function of number $(N)$ of pulse amplitude channel (upper scale) or the energy loss of gamma-rays $(\varepsilon)$ in the detector volume (lower scale).

Amplitude spectrum $S_{\gamma}(\varepsilon)$ is proportional to inclusive spectrum $\sigma_{\gamma}\left(E_{\gamma}, \theta_{\gamma}\right)$ of gamma-rays emitted from all possible $(\mathrm{n}, \mathrm{x} \gamma)$ reactions at the angle $\theta_{\gamma}$ near $90^{\circ}$ to the neutron beam direction and is given by the following expression:

$$
S_{\gamma}(\varepsilon)=\int_{0}^{E_{\max }} \chi_{S}\left(\varepsilon, E_{\gamma}\right) \sigma_{\gamma}\left(E_{\gamma}, \theta_{\gamma}\right) d E_{\gamma},
$$

where $E_{\gamma}$ is $\gamma$-ray energy with maximal value $E_{\max }$; $\chi_{S}\left(\varepsilon_{\gamma}, E_{\gamma}\right)$ is the total response function of spectrometer:

$$
\begin{gathered}
\chi_{S}\left(\varepsilon, E_{\gamma}\right)=N_{n} \cdot \alpha_{n} \cdot N_{S} \cdot \alpha_{\gamma}\left(E_{\gamma}\right) \times \\
\times \Delta \Omega \cdot \varepsilon_{d}\left(E_{\gamma}\right) \cdot \chi_{\Delta \varepsilon}\left(\varepsilon, E_{\gamma}\right), \\
\chi_{\Delta \varepsilon}\left(\varepsilon, E_{\gamma}\right)=\int_{\varepsilon-\Delta \varepsilon / 2}^{\varepsilon+\Delta \varepsilon / 2} \chi_{d}\left(\varepsilon^{\prime}, E_{\gamma}\right) d \varepsilon^{\prime} .
\end{gathered}
$$

Here, $N_{n}$ is the total fluence of the incident neutrons during time of measurement; $\alpha_{n}$ - correction factor determining the incident neutron absorption in the sample; $N_{S}$ - the number of target nuclei; $\alpha_{\gamma}\left(E_{\gamma}\right)$ - correction function on self-absorption of $\gamma$-ray with energy $E_{\gamma}$ in the torus sample; $\Delta \Omega$ is the detection solid angle; $\varepsilon_{d}\left(E_{\gamma}\right)$ is the $\mathrm{NaI}(\mathrm{Tl})$ detector efficiency. A function $\chi_{\Delta \varepsilon}\left(\varepsilon, E_{\gamma}\right)$ is total response function of the the $\mathrm{NaI}(\mathrm{Tl})$ detector for gamma-ray with energy $E_{\gamma}$ from interval $\Delta \varepsilon$ with $\chi_{d}\left(\varepsilon, E_{\gamma}\right)$ for the normalized response function $\int_{0}^{\infty} \chi_{d}\left(\varepsilon, E_{\gamma}\right) d \varepsilon=1$.

We used the results from previous studies for $\chi_{d}\left(\varepsilon, E_{\gamma}\right)[2-9]$ and adopted the following closedform expression, which was derived based on the corresponding measurements presented in Ref. [9] for bremsstrahlung with energies $E_{\gamma}=2 \div 25 \mathrm{MeV}$ :

$$
\chi_{d}\left(\varepsilon, E_{\gamma}\right)=b_{1} \cdot \frac{E_{\gamma}-\left(1-b_{2}\right) \cdot \varepsilon+b_{3}}{\left(E_{\gamma}-\varepsilon+b_{3}\right)^{2}+b_{4} \cdot \varepsilon}+b_{5} \text {, }
$$

where $b_{1}=11.945 \cdot\left(E_{\gamma}+4.54\right)^{-1.5}, b_{2}=0.104 \cdot E_{\gamma}^{0.12}$, $b_{3}=0.0573 \cdot\left(E_{\gamma}+0.25\right)^{-0.11}+0.303, \quad b_{4}=0.14$ and $b_{5}=0.00458 \cdot E_{\gamma}^{0.435}$ with energies in $\mathrm{MeV}$.

The total fluence $N_{n}$ of the incident neutrons was calculated in approximation of a circular ring sample of the radius $R_{S}=10 \mathrm{~cm}$ by the formula $N_{n}=F / 4 \pi R_{s}^{2}=8.36 \cdot 10^{7} \mathrm{~cm}^{-2}$ with $F=1.05 \cdot 10^{11}$ for the total number of generated neutrons in $4 \pi$ solid angle ( $N_{n}$ value in $\mathrm{cm}^{-2}$ corresponds to $\sigma_{\gamma}$ in $\mathrm{cm}^{2}$ ). The $F$ was measured by the PS detector and an approximation of a small value of the minor torus radius was used $\left(r_{S} / R_{S}=0.15<<1\right)$. The number of nuclei in the sample was equal to $N_{S}=N_{A} m_{S} / m_{N i}=3.68 \cdot 10^{25}$, where $N_{A}$ is the Avogadro constant, $m_{S}=3588 \mathrm{~g}$ and $m_{N i}=58.69 \mathrm{~g}$ are sample mass and molar mass of $\mathrm{Ni}$.

For calculations of the self-absorption factors, a circular section of a torus was approximated by square section of equal area [10] with a side $h=\sqrt{\pi} \cdot r_{S}=2.6 \mathrm{~cm}$. The correction factor on the incident neutron absorption in the sample was calculated in the two dimensional ring geometry in the following way [11]:

$$
\alpha_{n}=\int_{r_{1}}^{r_{2}} e^{-n_{s} \cdot \sigma_{\text {inel }}\left(\mathrm{E}_{n}\right) \cdot\left(\mathrm{r}-\mathrm{r}_{1}\right)} \frac{d r}{r} / \int_{r_{1}}^{r_{2}} \frac{d r}{r}=0.853,
$$

where $r_{1}=R_{S}-h / 2, r_{2}=R_{S}+h / 2$ are inner and outer radii of the ring and $n_{s}=9.1 \cdot 10^{22} \mathrm{~cm}^{-3}$ is average concentration of the $N i$ nuclei. The evaluated value $\sigma_{\text {inel }}=1.42 b$ was adopted for inelastic cross section of the $14.1 \mathrm{MeV}$ neutrons on nickel from evaluated data file ENDFB-V (experimental values for $\sigma_{\text {inel }}$ from EXFOR database varied from this value on $\sim 3 \%$ ). The $\gamma$-ray self-absorption func- 
tion in the sample was estimated as $\alpha_{\gamma}=\left(1-e^{-\mu_{\gamma s} \cdot h}\right) /\left(\mu_{\gamma s} \cdot h\right)$, where $\mu_{\gamma s}$ is the linear attenuation coefficient for $\gamma$-rays with energy $E_{\gamma}$ in ${ }^{n a t} \mathrm{Ni}$. The values of the coefficients $\mu_{\gamma s}$ were calculated by the use of photon cross section database XCOM [12].

Due to the long flight path $\left(R_{S} / L_{F}=0.06\right)$ the detection solid angle was calculated for a circular ring geometry by the formula [13]:

$$
\Delta \Omega=4 \pi \mathrm{G}\left(\mathrm{R}_{\mathrm{S}}, \mathrm{r}_{\mathrm{d}}, \mathrm{L}_{\mathrm{F}}\right)=5.67 \cdot 10^{-3} s r,
$$

where $G$ is geometric efficiency ("geometry factor") for parallel placed planes of the ring sample and detector

$$
\begin{gathered}
\mathrm{G}\left(\mathrm{R}_{\mathrm{S}}, \mathrm{r}_{\mathrm{d}}, \mathrm{L}_{\mathrm{F}}\right)= \\
=\frac{r_{d} L_{\mathrm{F}}}{2 \pi} \int_{0}^{\pi} \frac{\cos t \cdot\left(\mathrm{r}_{d} \cos \mathrm{t}-\mathrm{R}_{\mathrm{S}}\right) \mathrm{dt}}{\left(\mathrm{r}_{d}^{2} \sin ^{2} \mathrm{t}+\mathrm{L}_{F}^{2}\right) \cdot \sqrt{R_{S}^{2}+\mathrm{r}_{d}^{2}+L_{F}^{2}-2 r_{d} R_{\mathrm{S}} \cos t} .} .
\end{gathered}
$$

The NaI(Tl) detector intrinsic efficiency was calculated within the "efficiency transfer" principle [14] with efficiency for point radiation source

$$
\varepsilon_{d}\left(E_{\gamma}\right)=T_{P}\left(E_{\gamma}\right) \cdot 4 \pi / \Delta \Omega_{P},
$$

where $T_{P}\left(E_{\gamma}\right)$ is a corresponding total absolute detector efficiency [15]

$$
\begin{gathered}
T_{P}\left(E_{\gamma}\right)=\frac{1}{2} \cdot\left\{\int _ { 0 } ^ { \operatorname { t a n } ^ { - 1 } ( \frac { r _ { d } } { L _ { F } + h _ { d } } ) } \left[1-e^{\left.-\mu_{\gamma d} \cdot \frac{h_{d}}{\cos (\theta)}\right] \cdot \sin (\theta) \mathrm{d} \theta+}\right.\right. \\
\left.+\int_{\tan ^{-1}\left(\frac{r_{d}}{L_{F}+h_{d}}\right)}^{\tan ^{-1}\left(\frac{\left.r_{d}\right)}{L_{F}}\right)}\left[1-e^{-\mu_{\gamma d} \cdot\left(\frac{r_{d}}{\sin (\theta)}-\frac{L_{F}}{\cos (\theta)}\right)}\right] \cdot \sin (\theta) \mathrm{d} \theta\right\},
\end{gathered}
$$

$\mu_{\gamma d}$ is the linear attenuation coefficient for gammarays in NaI compound [12] and $\Delta \Omega_{P}$ is the solid angle subtended by the cylindrical detector at the source point

$$
\Delta \Omega_{P}=2 \pi\left[1-\left\{1+\left(\frac{r_{d}}{L_{F}}\right)^{2}\right\}^{-1 / 2}\right] .
$$

The results of the calculations are presented in Fig. 3. At the energies above $\sim 5 \mathrm{MeV}$ the main mechanism by which photons are detected is the creation of electron-positron pairs, and therefore the detector efficiency rises with energy because of increasing the pair production cross section.

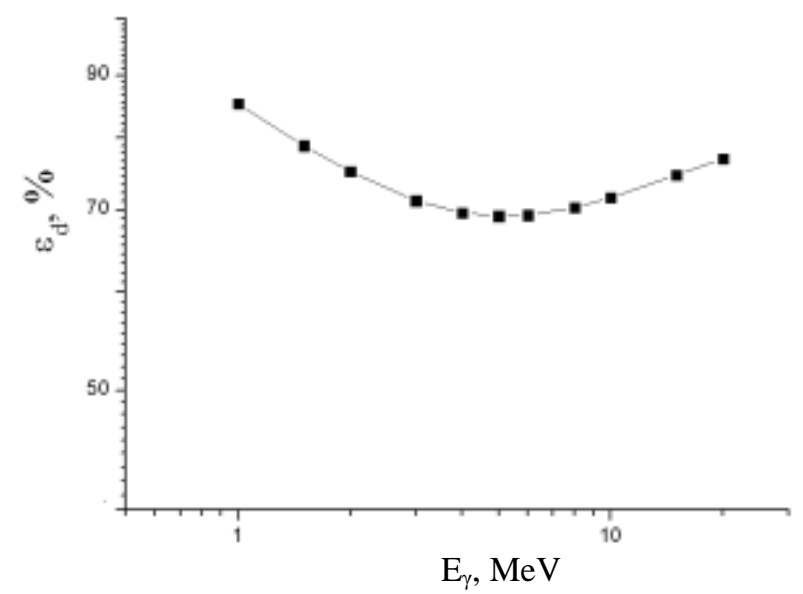

Fig. 3. Detector efficiency $\varepsilon_{d}$ of the $\mathrm{NaI}(\mathrm{Tl})$

$(150 \times 100 \mathrm{~mm})$ versus gamma-ray energy $E_{\gamma}$.

For unfolding the gamma-ray spectrum $\sigma_{\gamma}\left(E_{\gamma}, \theta_{\gamma}\right)$ from the amplitude spectrum $S_{\gamma}(\varepsilon)$, the numerical method of approximate solution of ill-posed problem on the compact set [16] was used for solution of the Fredholm integral equation of the first kind (1) (see Refs. [2 - 9]). Uncertainties of the cross section were estimated in assumption that the amplitude spectrum is followed by Gauss distributions due to the large number of external independent factors.

In Fig. 4 the experimental unfolded spectrum and its uncertainties with the experimental data from EXFOR data base (Refs. [17 - 20]) are shown. Here our results and experimental data from Refs. [17 19] are multiplied by factor $4 \pi$, i.d., they can be considered as the angle integrated gamma-ray spectrum $\sigma_{\gamma}\left(E_{\gamma}\right) \equiv d \sigma_{\gamma}\left(E_{\gamma}\right) / d E_{\gamma}=4 \pi \sigma_{\gamma}\left(E_{\gamma}, \theta_{\gamma}\right)$ due to weak dependence of the differential cross sections on gamma-emission angle.

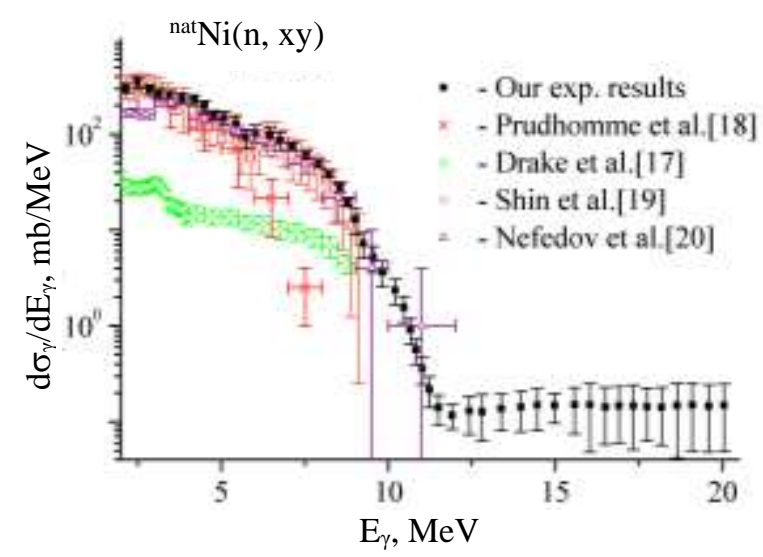

Fig. 4. The measured gamma spectrum from fast neutron capture in ${ }^{\text {nat }} \mathrm{Ni}$ in comparison with experimental data from Refs. [17 - 20]. (See color Figure on journal website.)

One can see in Fig. 4 that for the gamma-ray energy interval $2 \div 6 \mathrm{MeV}$ the experimental data are in close agreement with the data from EXFOR database except of results by Drake et al.[17]. Measured 
gamma-ray spectrum smoothly decreases with gamma-ray energy. For higher energy range $12 \div 20 \mathrm{MeV}$, the differential cross section $\mathrm{d} \sigma_{\gamma} / \mathrm{dE}_{\gamma}$ was measured for the first time and has almost constant value.

\section{Comparison with theoretical calculations}

For mono-isotope targets with nuclei $\left(A_{i}, Z\right)$, the gamma spectrum $\left(\sigma_{\gamma}^{i}\left(E_{\gamma}\right)\right)$ is a sum of gamma-ray spectra from all nuclear reactions with emission of all possible particles and gamma-rays

$$
\sigma_{\gamma}^{i}\left(E_{\gamma}\right) \equiv \sum_{x} d \sigma\left(A_{i}(n,\{x, \gamma\})\right) / d E_{\gamma},
$$

where symbol $\{x, \gamma\}$ denotes final channels with arbitrary sequence of emission particles and gammarays. In the case of targets with natural elements the gamma spectrum is a sum of the component (8) weighted by a factor $w_{i}$ corresponding to abundance $\alpha(\%)$ of the isotopes

$$
\begin{gathered}
\sigma_{\gamma}\left(E_{\gamma}\right)=\sum_{i} w_{i} \cdot \sigma_{\gamma}^{i}\left(E_{\gamma}\right) \equiv \\
\equiv \sum_{i} w_{i} \cdot \sum_{x} d \sigma\left(A_{i}(n,\{x, \gamma\})\right) / d E_{\gamma}, \quad w_{i}=\alpha_{i} / 100 .
\end{gathered}
$$

Comparison of the experimental and theoretical gamma spectrum $\sigma_{\gamma}\left(E_{\gamma}\right)$ from fast neutron capture in ${ }^{\text {nat }} \mathrm{Ni}$ is presented in Fig. 5. The nuclear reactions on the following isotopes were taken into account in the calculations: ${ }^{58} \mathrm{Ni}(68.077 \%),{ }^{60} \mathrm{Ni}(26.223 \%)$, ${ }^{61} \mathrm{Ni}(1.14 \%),{ }^{62} \mathrm{Ni}(3.634 \%)$ and ${ }^{64} \mathrm{Ni}(0.926 \%)$, where abundance is indicated in brackets.

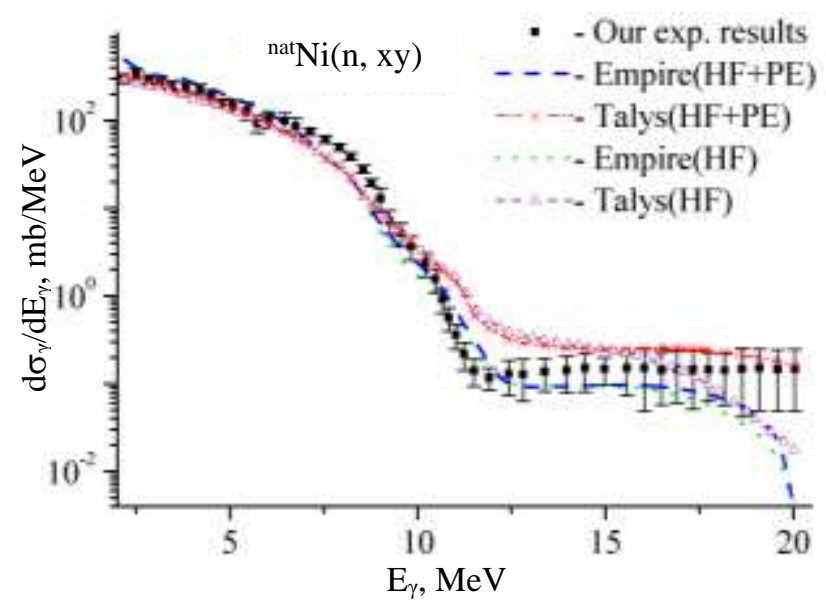

Fig. 5. Comparison of the experimental and theoretical gamma spectrum from fast neutron capture in ${ }^{\text {nat }} \mathrm{Ni}$. (See color Figure on journal website.)
Calculations were performed using the EMPIRE 3.2 and TALYS 1.6 codes $[21,22]$ with allowance for the emission of particles and gamma-rays from equilibrium and pre-equilibrium states using the default sets of the input parameters, specifically, for EMPIRE code, these parameters are Modified Lorentzian model (MLO1) for the electric dipole photon strength function (PSF) and Enhanced Generalized Super-Fluid Model (EGSM) for nuclear level density (NLD) model. Calculations were performed with preequilibrium processes (PE) (parameter PCROSS $=1.5)$ and without PE $($ PCROSS $=0)$. For TALYS code, default parameters are Enhanced Generalized Lorentzian (EGLO) for PSF and Gilbert - Cameron approach (GC) for NLD. Global optical potential given by Koning - Delaroche [23] is adopted as default in the calculations within two codes.

It can be seen from Fig. 5 that there is rather good agreement between different theoretical calculations and the experimental data in the gamma-ray energy interval $2 \div 10 \mathrm{MeV}$. For high energy range $10 \div 20 \mathrm{MeV}$, the calculations within TALYS code lead to higher values of the gamma-ray spectrum and better agree with experimental data. It indicates on important role of the preequilibrium processes.

In order to check the sensitivity of the calculated gamma spectra to the PSF and the NLD, the calculations were performed within EMPIRE code $($ PCROSS $=1.5)$. For the PSF, the following methods [24 - 26] were used: the EGLO model (according to RIPL-2 [24]), MLO1 and MLO4 variants of MLO approach, Standard Lorentzian model (SLO) and Generalized Fermi Liquid (GFL) model. For the NLD, we used the EGSM, Generalized Superfluid Model (GSM), Gilbert and Cameron (CG) model (from EMPIRE 2.18), microscopic combinatorial level densities within Hartree - Fock - Bogoliubov method (HFBM) and Modified Generalized SuperFluid Model with Bose attenuated numbers for vibrational enhancement factor (MEGSM) [24, 27].

From Fig. 6 it follows that there is only small difference between calculated gamma spectra using different PSF models (except EGLO method). The calculations with the use of different NLD approaches are also in rather good agreement. For EMPIRE code, the best agreement with the experiment was obtained in a case of using MLO1 or MLO4 for the PSF and EGSM or MEGSM for the NLD. It should be noted that the calculations of high energy part of gamma-ray spectrum with $E_{\gamma}=$ $=14 \div 20 \mathrm{MeV}$ within TALYS code better agree with the experimental data. 


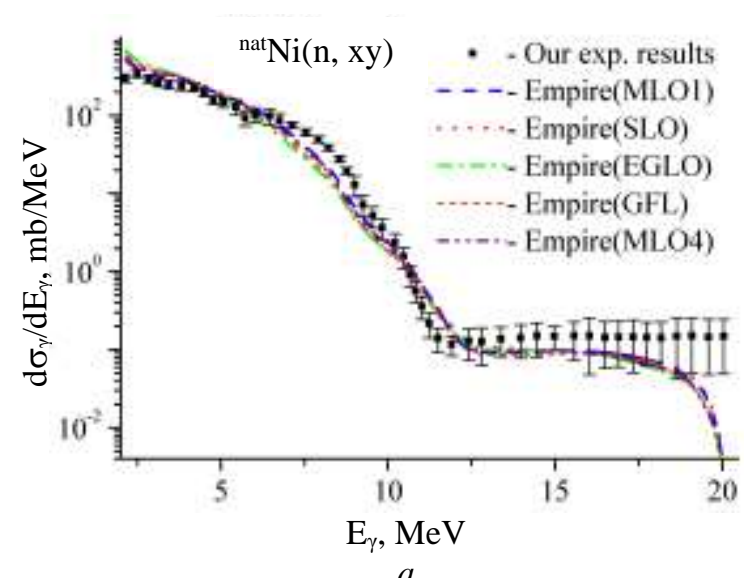

$a$

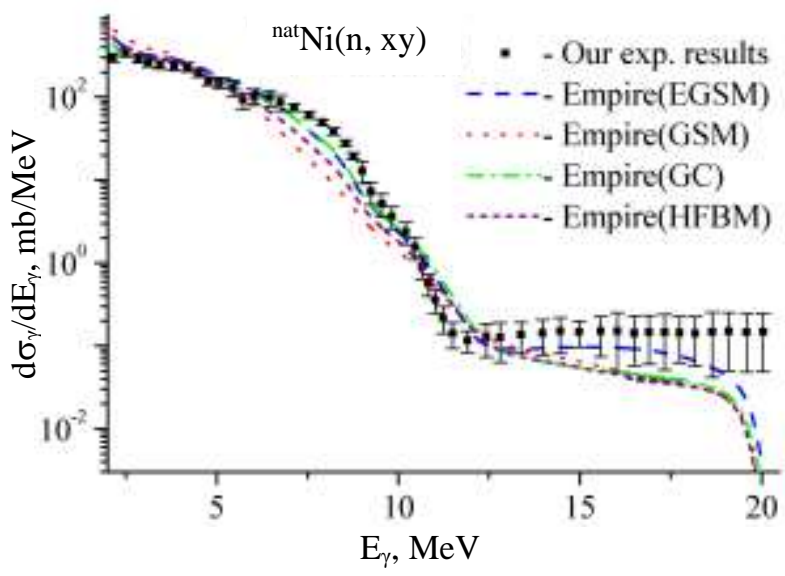

b

Fig. 6. The gamma spectrum from fast neutron capture in ${ }^{\text {nat }} \mathrm{Ni}$ calculated with EMPIRE 3.2 code using different models for the PSF $(a)$ and NLD $(b)$.

(See color Figure on journal website.)

\section{Conclusions}

The measurements of gamma-ray spectra induced by interactions of $14 \mathrm{MeV}$ neutrons with ${ }^{\text {nat }} \mathrm{Ni}$ nuclei were performed by the time-of-flight technique and inclusive differential cross section of corresponding $(n, x \gamma)$ reactions were unfolded from amplitude spectrum using numerical method for solution of ill-posed problem.

In gamma-ray energy interval $2 \div 6 \mathrm{MeV}$ the experimental data are in a rather good agreement with the data from EXFOR database except of the results by Drake et al [17]. For high energy range $12 \div 20 \mathrm{MeV}$, the differential cross section was measured for the first time and has almost constant value $\sim 0.15 \mathrm{mb} / \mathrm{MeV}$.
The theoretical calculations were performed within framework of statistical models of compound and precompound decays by the use of EMPIRE 3.2 and TALYS 1.6 codes. For gamma-ray energies up to $\sim 10 \div 12 \mathrm{MeV}$, much better agreement between experimental and theoretical results is obtained using input parameters for photon strength function and nuclear level density by default. For higher gamma-ray energies with values $14 \div 20 \mathrm{MeV}$, the TALYS calculations with allowance for preequilibrium emission better agree with the experimental data.

This work is supported in part by the IAEA (Vienna) under IAEA Research Contract within CRP No.F41032.

\section{REFERENCES}

1. Forrest R.A. Nuclear data for fusion applications // Proc. Int. Conference on Nuclear Data for Science and Technology (ND2007), May 22-27, 2007. - Nice, France, 2007. - P. 11 - 16.

2. Prokopets G.O., Leshchenko B.Yu., Onishchuk Yu.M., Basenko V.K. Differential cross sections of prompt $\gamma$ rays in reactions produced by $14 \mathrm{MeV}$ neutrons // Bulletin of the Kiev University. Physical and mathematical Science. - 1997. - Vol. 3. - P. 423 - 434. (Ukr)

3. Onishchuk Yu.M., Leshchenko B.Yu. Problems with the processing of hardware gamma spectra of inelastic interaction of $14 \mathrm{MeV}$ neutrons with nuclei // Zbirnyk naukovykh prats In-tu yadernykh doslidzhen. - 1999. P. 127 - 129. (Ukr)

4. Onishchuk Yu.M., Leshchenko B.Yu. Methods of recovery from hardware gamma spectra cross section of gamma rays in a wide energy range by the interaction of $14.1 \mathrm{MeV}$ neutrons with atomic nuclei // Materials of scientific-theoretical conference in honour of 165th anniversary of the Kyiv National University (Natural Sciences). - Kyiv, Kyiv University, 1999. - P. 47 $52(\mathrm{Ukr})$
5. Bondar V.M., Kadenko I.M., Leshchenko B.Yu. et al. Cross section of $\gamma$-rays irradiation in reactions of neutron absorption by iron // Yaderna fizyka ta atomna energetyka (Nucl. Phys. At. Energy). - 2008. Vol. 1(23). - P. 16 - 23. (Ukr)

6. Bondar V.M., Kadenko I.N., Leshchenko B.E. et al. Cross section of prompt gamma-ray production by fast neutrons on iron and bismuth nuclei // Bulletin of the Russian Academy of Sciences: Physics. - 2009. Vol. 73(11). - P. 1511 - 1514. (Rus)

7. Bondar V.M., Gorbachenko O.M., Kadenko I.M. et al. Spectra of gamma-rays in $(\mathrm{n}, \mathrm{x} \gamma)$ reactions on ferrum and bismuth nuclei // Yaderna fizyka ta atomna energetyka (Nucl. Phys. At. Energy). - 2010. - Vol. 11(3). - P. 246 - 251.

8. Bondar B.M., Bondar V.M., Gorbachenko O.M. et al. Cross sections of prompt $\gamma$-ray production induced by interactions of fast neutrons with cadmium // Yaderna fizyka ta atomna energetyka (Nucl. Phys. At. Energy). - 2011. - Vol. 12(2). - P. 129 - 136 (Ukr)

9. Gurevich G.M., Mazur V.M., Solodukhov G.V. Apparatus function of scintillation $\gamma$-spectrometer based on 
large $\mathrm{NaI}(\mathrm{Tl})$ detector // Instruments and Experimental Techniques. - 1975. - Vol. 2. - P. 59 - 62. (Rus)

10. Gardner R.P., Carnesale A. Conway J.T. The solid angle subtended at a point by a circular disk // Nuclear instruments and methods. - 1969. - Vol. 73. - P. 228 230.

11. Van Patter D.M., Nath N., Shafroth S.M. et al. Gamma Rays from Inelastic Neutron Scattering in Chromium // Phys. Rev. - 1962. - Vol. 128 - P. 1248 - 1267.

12. Berger M.J., Hubbell J.H., Seltzer S.M. et al. XCOM: Photon Cross Section Database (version 3.1) // http://physics.nist.gov/xcom - Gaithersburg, National Institute of Standards and Technology, 2010.

13. Conway J.T. Geometric efficiency for a circular detector and a ring source of arbitrary orientation and position // Nuclear instruments and methods in physics research. - 2011. - Vol. A640. - P. 99 - 109.

14. Jovanovic S., Dlabac A., Mihaljevic N. ANGLE v2.1 New version of the computer code for semiconductor detector gamma-efficiency calculations // Nuclear instruments and methods in physics research. - 2010. Vol. A622. - P. 385 - 391.

15. Heath R.L. Scintillation Spectrometry: Gamma-ray Spectrum Catalogue / Revised edition of IDO - 168801, Original issued: August 1964, Rev. Electronic report update: February 1997. - Vol. 1.

16. Tikhonov A.N., Goncharsky A.V., Stepanov V.V. et al. Numerical methods for the solution of ill-posed problems. - Moscow, 1995. - 253 p.

17. Drake D.M., Arthur E.D., Silbert M.G. Cross section for gamma-ray production by $14-\mathrm{MeV}$ neutrons// Nuclear Science and Engineering. - 1978. - Vol. 65. P. 49 - 64. EXFOR subentry \#10684010.

18. Prud'homme J.T., Morgan I.L., McCrary J.H. et al. A study of neutrons and gamma rays from neutron induced reactions in several elements // Rept: Air Force Spec. Weap. Center, Kirtland A.F.B.Reports. - 1960 No. 60 - P. 30. EXFOR subentry \#11183010.

19. Shin K., Hasegawa T., Hyodo T. (n, x $\gamma)$ and (n, xn) cross sections of molybdenum, titanium and nickel for
15-MeV neutrons // Jour. Nuclear Science and Technology. - 1980. - Vol. 17, Iss. 7. - P. 531 - 538. EXFOR subentry \#21727004.

20. Nefedov Yu.Ya., Nagornyj V.I., Semenov V.I. et al. Gamma-ray production cross-section and spectrum measurement results for inelastic interaction of $14 \mathrm{MeV}$ neutrons with nuclei of $\mathrm{Na}, \mathrm{S}, \mathrm{Cl}, \mathrm{Ti}, \mathrm{V}, \mathrm{Cr}$, $\mathrm{Ni}, \mathrm{Zn}, \mathrm{Ge}, \mathrm{Nb}, \mathrm{Cd}, \mathrm{In}, \mathrm{Sn}, \mathrm{Bi},{ }^{235} \mathrm{U}$ and ${ }^{238} \mathrm{U} / /$ Problems of Atomic Science and Technology. Series: Nuclear Constants. - 2000 - Iss. 1. - P. 7. (Rus). EXFOR subentry \#41379008.

21. Herman M., Capote R., Carlson B.V. et al. EMPIRE: Nuclear Reaction Model Code System for Data Evaluation // Nuclear Data Sheets. - 2007. - Vol. 108. P. 2655 - 2715; http://www.nndc.bnl.gov/empire/

22. Koning A.J., Hilaire S., Duijvestijn M. C. TALYS-1.0 // Proc. of the Intern. Conf. on Nuclear Data for Science and Technology, ND2007, April 22 - 27, 2007, Nice, France. - 2007. - P. 211 - 214; http://www.talys.eu/.

23. Koning A.J., Delaroche J.P. Local and global nucleon optical models from $1 \mathrm{keV}$ to $200 \mathrm{MeV} / /$ Nucl. Phys. - 2003. - Vol. A713. - P. 231 - 310.

24. Capote R., Herman M., Oblozinsky P. et al. Parameters for calculation of nuclear reactions of relevance for energy and non-energy nuclear applications // Nuclear Data Sheets - 2009 - Vol. 110 - P. 3107 - 3214; http://www-nds.iaea.org/RIPL-3/.

25. Plujko V.A., Capote R., Gorbachenko O.M. Giant Dipole Resonance parameters with uncertainties from photonuclear cross sections // Atomic Data and Nuclear Data Tables. - 2011. - Vol. 97. - P. 567 - 589.

26. Plujko V.A., Gorbachenko O.M., Rovenskykh E.P., Zheltonozhskii V.A. Average description of dipole gamma transitions in hot atomic nuclei // Nuclear Data Sheets. - 2014. - Vol. 118. - P. 237 - 239.

27. Plujko V.A., Gorbachenko O.M., Bondar B.M., Rovenskykh E.P. Nuclear level density within extended superfluid model with collective state enhancement // Nuclear Data Sheets. - 2014. - Vol. 118. - P. 240 - 242.

\author{
І. М. Каденко ${ }^{1}$, В. А. Плюйко ${ }^{1}$, Б. М. Бондар ${ }^{1,2}$, \\ О. М. Горбаченко ${ }^{1}$, Б. Ю. Лещенко ${ }^{1,3}$, К. М. Солодовник ${ }^{1}$ \\ ${ }^{1}$ Київський національний університет імені Тараса Шевченка, Київ \\ ${ }^{2}$ Всеукраӥнський центр радіохірургії клінічної лікарні «Феофанія», Київ \\ ${ }^{3}$ Національний технічний університет Украӥни «Київський політехнічний інститут», Київ
}

\title{
МИТТЕВІ ГАММА-КВАНТИ ПРИ ПОГЛИНАННІ ШВИДКИХ НЕЙТРОНІВ ЯДРАМИ ${ }^{\text {nat }} \mathrm{Ni}$
}

Проведено вимірювання спектрів миттєвих гамма-квантів при взаємодії нейтронів $14 \mathrm{MeB} 3$ ядрами ${ }^{\text {nat }} \mathrm{Ni} 3$ використанням часопролітної методики. 3 амплітудного спектра відновлено диференціальні перерізи (n, хү) реакцій з оцінкою похибок. Експериментальні результати було порівняно з теоретичними розрахунками, виконаними в кодах Empire 3.2 та Talys 1.6. Досліджено чутливість обчислених величин перерізів до характеристик збуджених ядерних станів.

Ключові слова: реакції з нейтронами, часопролітна методика, гамма-спектр, статистична теорія Хаузера Фешбаха, радіаційна силова функція, густина ядерних рівнів. 


\title{
И. Н. Каденко1, В. А. Плюйко ${ }^{1}$, Б. М. Бондарь ${ }^{1,2}$,
}

\author{
А. Н. Горбаченко ${ }^{1}$, Б. Е. Лещенко ${ }^{1,3}$, Е. Н. Солодовник ${ }^{1}$
}

${ }^{1}$ Киевский национальный университет имени Тараса Шевченко, Киев

${ }^{2}$ Всеукраинский иентр радиохирургии клинической больницы «Феофания», Киев

${ }^{3}$ Национальный технический университет Украиньл «Киевский политехнический институт», Киев

\section{МГНОВЕННЫЕ ГАММА-КВАНТЫ ПРИ ПОГЛОЩЕНИИ БЫСТРЫХ НЕЙТРОНОВ ЯДРАМИ ${ }^{\text {nat }} \mathrm{Ni}$}

Измерены спектры мгновенных гамма-квантов при взаимодействии 14 МэВ нейтронов с ядрами ${ }^{\text {nat }} \mathrm{Ni}$ с использованием времяпролетной методики. Из амплитудного спектра восстановлены дифференциальные сечения $(\mathrm{n}, \mathrm{x} \gamma)$ реакций и их погрешности. Экспериментальные результаты сравниваются с соответствующими теоретическими расчетами, выполненными с использованием кодов EMPIRE 3.2 и TALYS 1.6. Исследована чувствительность вычисленных спектров гамма-квантов к характеристикам возбужденных ядерных состояний.

Ключевые слова: реакции с нейтронами, времяпролетная методика, гамма-спектр, статистическая теория Хаузера - Фешбаха, радиационная силовая функция, плотность ядерных уровней.

Надійшла 18.05.2016

Received 18.05.2016 